\title{
The European Scientific Conference on Applied INFECTIOUS DISEASE EPIDEMIOLOGY (ESCAIDE) - SELECTED PAPERS FROM THE CONFERENCE 2008
}

\author{
The ESCAIDE Scientific Committee (Ines.Steffens@ecdc.europa.eu) ${ }^{1}$ \\ 1. Members of the scientific committee are listed at the end of the editorial
}

\section{This article was published on 29 October 2009.}

Citation style for this article: The ESCAIDE Scientific Committee. The European Scientific Conference on Applied Infectious Disease Epidemiology (ESCAIDE) - selected papers from the conference 2008. Euro Surveill. 2009;14(43):pii=19377. Available online: http://www.eurosurveillance.org/ViewArticle.aspx?ArticleId=19377

This issue of Eurosurveillance has two focuses: a special issue on capacity building and training for applied field epidemiology in Europe [1] and a focus on the European Scientific Conference on Applied Infectious Disease Epidemiology (ESCAIDE) by featuring two papers based on presentations made at ESCAIDE 2008. The authors of these papers were invited by the Eurosurveillance editors to submit an article for peer-review after the abstract selection had taken place, because of their overall quality and the focus on information for action. In their contribution from Thailand, Pawun et al. report on a field-investigation of a nosocomial outbreak of bullous impetigo in newborns, caused by Staphyloccoccus aureus, in a hospital in northern Thailand [2]. The results from this investigation lead to the implementation of immediate measures that stopped the outbreak. Moreover, the awareness raised of the problems identified during the investigation triggered the implementation of measures to prevent similar outbreaks in the future. The second paper by Girardi et al. reports on the diagnosis of latent tuberculosis infection, an issue of considerable debate [3]. The authors compare sensitivity and specificity of interferongamma assays for latent tuberculosis infection by assessing the association of test results with tuberculosis occupational exposure in 115 health care workers by using latent class analysis. They found that the estimated specificity of in vitro assays was higher than that of Tuberculin skin tests (TST) also among individuals who were not BCG-vaccinated and from their data the authors conclude that when applied in healthcare workers, in vitro assays may provide a significant increase of specificity for tuberculosis infection compared to TST, even among non-vaccinated individuals, at the cost of some sensitivity.

The two papers presented serve as good examples for some of the unique features of ESCAIDE; the conference's focus not only on applied science and epidemiology (including field investigations), but on the direct, concrete application of study results for public health action. ESCAIDE is supported by European Centre for Disease Control and Prevention (ECDC) and jointly organised by ECDC, the European Programme for Intervention Epidemiology Training (EPIET), the EPIET Alumni Network (EAN) and the Training Programs in Epidemiology and Public Health Intervention NETwork (TEPHINET EUROPE). Besides sharing scientific knowledge, ESCAIDE provides an excellent opportunity for experts with a wide range of various backgrounds who are involved in epidemiology and infectious disease control and prevention to strengthen and expand networks and share experiences. The first ESCAIDE took place in October 2007 in Stockholm and was followed by a conference in
Berlin in October 2008. At the time of publication of this editorial, the third ESCAIDE in Stockholm has just come to its end. From start, ESCAIDE has been a success with constantly well over 600 visitors and an annual increase of submitted abstracts of around 10 percent. Even if the focus of the conference is Europe, its' reach is global; in 2009, besides from Europe, participants came from Australia, Brazil, Canada, China, Hong Kong, New Zealand, Pakistan, the Philippines, Thailand, the Unites States and Vietnam. Pandemic H1N1 influenza has understandably been given some focus during the 2009 conference. However, as in previous years, many other topics were covered in the various sessions. Topics covered by plenary sessions ranged from ageing and infectious diseases to influenza vaccination and to new methods for analysing outbreaks. A new and special focus on this year's ESCAIDE meeting was the viewpoint from the laboratory and its role in public health, with a plenary session on what genotyping has to offer epidemiologists. More specific information on the conference can be found on a dedicated website (www.escaide.eu/) [4].

Given that ESCAIDE is both a forum for exchanging scientific knowledge and good practice as well as for networking and personal professional development, the two focuses of this Eurosurveillance issue stand well side-by-side: ESCAIDE and capacity building and training for applied field epidemiology in Europe.

Members of the ESCAIDE scientific committee are: Andrea Ammon, ECDC, Arnold Bosman, ECDC, Viviane Bremer, ECDC/EPIET, Johan Giesecke, ECDC (chair), Gérard Krause, ECDC Advisory Forum, Marion Koopmans, European Society for Clinical Virology , Eavide Advisory Forum, Marion Koopmans, Eur Gean Society for Clinical Virology, Davide Manissero, ECDC, Banbara , Panayotis Tassios, European Society of Clinical Microbiology and Infectious Diseases.

\section{References}

1. Walke HT, Simone PM. Building capacity in field epidemiology: lessons learned from the experience in Europe. Euro Surveill. 2009;14(43):pii=19376. Available from: http://www.eurosurveillance.org/ViewArticle.aspx?ArticleId=19376

2. Pawun V, Jiraphongsa C, Puttamasute S, Putta R, Wongnai A, Jaima T, et al. An outbreak of hospital-acquired Staphylococcus aureus skin infection among newborns, Nan Province, Thailand, January 2008. Euro Surveill. 2009;14(43):pii=19372. Available from: http://www.eurosurveillance.org/ ViewArticle.aspx?ArticleId $=19372$

3. Girardi E, Angeletti C, Puro V, Sorrentino R, Magnavita N, Vincenti D, et al. Estimating diagnostic accuracy of tests for latent tuberculosis infection without a gold standard among healthcare workers. Euro Surveill. 2009;14(43):pij=19373. Available from: http://www.eurosurveillance.org/ ViewArticle.aspx?ArticleId $=19373$

4. ESCAIDE 2009 [Internet]. Stockholm: European Scientific Conference on Applied Infectious Disease Epidemiology. 2009. [cited 29 October 2009]. Available from: www.escaide.eu 